\title{
DE OBJETO A MÉTODO: NOTAS HISTÓRICAS SOBRE ESTATÍSTICA E PESOUISA SOCIAL
}

Tradução de Helena Vieira Leitão de Souza

A concepção estatístico-probabilística da realidade tornou-se um sistema de ideias que o homem contemporâneo naturalizou. Conceber os fatos da vida - inclusive aqueles da vida cotidiana - a partir de uma perspectiva estatística se encontra tão difundido que frequentemente nem sequer o homem de ciência se detém para pensar que se trata, na realidade, de uma construção sócio-histórica, um produto do pensamento humano, e não de uma característica natural intrínseca à realidade. O fato de ser concebida como dada demonstra o êxito histórico que tal construção alcançou. Hacking (1990) a descreve como um novo "estilo de raciocínio", ${ }^{1}$ que apresenta o resultado de um êxito quádruplo: metafísico, epistemológico, lógico e ético. ${ }^{2}$ Afirma também (1990: 1) que "o evento conceitual mais decisivo do século $\mathrm{XX}$ foi a descoberta de que o mundo não é determinado. A causalidade, por muito tempo bastião da metafísica, foi desacreditada" e paulatinamente emergiu uma nova forma de "conhecimento objetivo" - a estatística. Isso foi o corolário de um processo de transformação gradual no qual se distinguem três tradições intelectuais que se iniciam em meados do século XVII: a Political arithmetic inglesa, a Statistik alemã e a Théorie mathématique des probabilités francesa.

Os ingleses inauguraram uma tradição de pesquisa social empírica que utilizava como recurso dados numéricos. De seu encontro com a estatística universitária alemã - isto é, o estudo comparativo dos Estados - entre fins do século XVIII e princípios do XIX, se redefiniu a estatística como o estudo quantitativo da sociedade e da política. Pouco tempo depois, os cultivadores da nova disciplina começaram a usar os instrumentos da teoria matemática das probabilidades - já correntes em astronomia - e deste modo abriram o caminho a uma nova visão, baseada no registro das frequências observadas 
a fim de identificar regularidades estocásticas, o que por sua vez reforçou com novas bases o uso das probabilidades (Porter, 1986: 17).

Porém a interpretação das frequências se fazia à luz do paradigma científico então dominante: privilegiavam-se as ideias de tipicidade e normalidade, e desconsiderava-se a de variabilidade, considerada uma manifestação do erro. Somente quando esta última começou a ser reconhecida como um problema científico legítimo - na Inglaterra de finais do século XIX - se produziu a mudança de rumo que deu origem à teoria estatística moderna. Com efeito, foi neste período - e como resultado da busca de novos instrumentos matemático-probabilísticos adequados para a pesquisa dos fenômenos humanos - que a estatística adquiriu seu significado atual talvez mais difundido: a disciplina dedicada aos instrumentos conceituais e operativos para a análise quantitativa de dados.

Seguindo MacKenzie (1981: 7), por teoria estatística - ou estatística matemática, como a chama Porter (1986) - entendo algo distinto da "atividade de coleta de informação quantitativa normalmente executada pelas entidades oficiais e os cientistas sociais [...] e da teoria matemática das probabilidades". A teoria estatística define-se como "construção de um quadro teórico para a análise dos dados numéricos" e dos "instrumentos que podem ser usados" para tal fim (MacKenzie, 1981: 7). Este processo começou na Inglaterra por volta de 1870, quando Galton começou a trabalhar no desenho de técnicas estatísticas apropriadas para suas investigações sobre a herança, e seus primeiros resultados de destaque foram os conceitos e instrumentos da regressão e correlação.

Neste artigo reconstroem-se as três tradições intelectuais a que se fez referência, com o propósito de ilustrar as raízes da moderna teoria estatística no pensamento científico europeu. Também se põe em evidência o complexo processo histórico, social e cultural que acompanhou a mudança de sentido do termo "estatística", de características sociopolíticas do Estado a um conjunto de instrumentos conceituais e operativos para a análise dos dados.

\section{DA ARITMÉTICA POLÍTICA À ESTATÍSTICA}

Em sentido amplo, a estatística inglesa - enquanto atividade de coleta e organização de dados relativos ao Estado - remonta ao século XVII. É amplamente compartilhada a visão que atribui caráter fundador no campo do estudo estatístico dos problemas sociais ao trabalho de John Graunt (1662) Natural and political observations on the bills of mortality. ${ }^{3}$ Poucos anos mais tarde, William Petty, em carta de 17 de dezembro de 1672 a Lorde Anglesea, introduziu a expressão political arithmethic (Cullen, 1975) - antepassado verossímil da corrente social statistics - para designar este tipo de estudos: "O estudo 
sistemático dos números sociais no espírito da filosofia natural se originou durante o decênio de 1660, e se conheceu por quase um século e meio como political arithmetic. Seu propósito [...] era a promoção de uma política social sólida e bem informada" (Porter, 1986: 18).

Os London bills of mortality, única fonte de dados demográficos disponíveis no Reino Unido, eram um material pouco interessante do qual não obstante Graunt derivou amplas conclusões (Cullen, 1975). O aspecto mais importante não se encontra na coleta e organização dos dados em si mesmos, trabalho considerado incipiente a cargo de entidades públicas, que seguia uma tendência crescente em vários Estados europeus, particularmente na França e na Prússia. Seguindo Cullen, as questões de maior destaque incidem na análise destes dados, nas conclusões alcançadas, ${ }^{4}$ nas reflexões metodológicas ${ }^{5}$ e na justificativa de uma nova disciplina, a Political arithmetic. Assim, os London bills of mortality continuarão a inspirar o desenvolvimento da estatística por muitos anos, uma vez que motiva o reformista à coleta escrupulosa de dados como requisito fundamental de qualquer reforma social. Nas palavras de seu inspirador - e inventor de seu nome - o propósito da nova disciplina era a aplicação dos princípios de Bacon à arte de governar (Porter, 1986). Com efeito, seguindo uma perspectiva baconiana, propôs um paralelo entre o corpo natural e o corpo político: "Atuar no corpo político sem conhecer sua simetria, seu tecido e suas proporções, é tão superficial e irresponsável como são os procedimentos [...] dos empíricos (empiricks) ${ }^{6}$ [sobre o corpo natural]" (Petty, 1691: 129).

Segundo Lazarsfeld (1961), a ideia de que as questões sociais podem ser submetidas à análise quantitativa fundamenta-se no clima intelectual da era baconiana, pelo desejo de imitar o mais importante êxito das ciências naturais - a quantificação ${ }^{7}$ e pelas características que estavam adquirindo os estados nacionais, que exigiam uma base de informação para a tomada de decisões públicas. Mais especificamente, tiveram um papel fundamental o desenvolvimento do sistema de seguros para o qual era funcional uma sólida base numérica e a concepção mercantilista que fazia da população um fator crucial para a riqueza e o poder de uma nação.

A Political arithmetic foi definida como uma ciência das sociedades cujas conclusões dependiam de números e medidas. Por conseguinte, a qualidade dos dados devia melhorar, e não casualmente Petty promoveu a criação de um escritório central de estatísticas. No entanto, suas realizações foram muito limitadas, especialmente por seu escasso conhecimento matemático. Apesar dos esforços, a linha proposta por Petty não teve continuidade, perdendo força a expressão "aritmética política". Destino semelhante teve sua ideia de uma ciência de caráter interdisciplinar, um híbrido de todas as disciplinas sociais, capaz de usar técnicas quantitativas. A estatística social ficou confinada à demografia, processo que Cullen (1975) chama redução da aritméti- 
ca política à demografia. Até final do século XVII este tipo de estudos floresceu. Seu objetivo era descrever a situação dos Estados de uma perspectiva demográfica e construir tabelas destinadas a calcular os seguros e as taxas de juro anual, úteis ao recém-criado sistema de seguros.

De todo modo, uma importante linha de continuidade observa-se na permanência de perspectiva e justificativa idênticas de colocar o conhecimento estatístico à disposição do governo para a elaboração de política social. Essa justificativa será importante no desenvolvimento sucessivo da teoria estatística, devido à necessidade de resolver problemas de investigação ligados ao desejo de "melhorar" a sociedade. ${ }^{8}$

Nos 50 anos transcorridos entre 1780 de 1830 começaram a se manifestar sinais de expansão e diversificação das estatísticas sociais no Reino Unido. Foi instituído um censo nacional e reforçou-se o desenvolvimento das estatísticas médicas; além disso, propuseram-se novas técnicas de análise e aplicaram-se técnicas conhecidas a problemas até então não quantificados (Cullen, 1975). Naquele período introduziu-se o termo statistics na língua inglesa. Foi utilizado pela primeira vez em inglês na tradução que Hooper (1770) fez do vocábulo alemão Statistik. Seguindo a tradição alemã, o neologismo inglês statistics foi definido como a ciência que "ensina o ordenamento político dos estados modernos conhecidos no mundo". ${ }^{9}$ No entanto, o vocábulo tinha outra história na Alemanha, que remonta ao célebre Alfred Achenwall, professor em Göttingen.

Segundo Meitzen (1886), a estatística tem suas raízes na political arithmetic, inglesa, e na Universitätsstatistik, estatística universitária alemã. A segunda raiz, da qual deriva o termo, é uma tradição que considerava os aspectos relevantes de um Estado e para a qual os dados numéricos não eram necessariamente os mais importantes; com efeito, tinham um papel bem mais secundário (Lazarsfeld, 1961). No entanto, Hacking (1990) considera errôneo atribuir a uma única nação a exclusividade na tendência à coleta e organização dos dados, mas reconhece que foram os alemães que propuseram caracterizar os Estados através de suas estatísticas, ideia que se materializou por meio de três expressões.

A primeira, de tipo intelectual, é justamente a Universitätsstatistik, cuja origem é anterior ao trabalho de Achenwall. Com efeito, Westergaard (1932), por exemplo, conclui que a Statistik - como disciplina dedicada ao estudo comparado e sistemático dos Estados - já havia sido definida por Hermann Conring, com o nome de Staatenkunde, no século XVII. ${ }^{10}$ Antes disso, John (1884) havia sustentado que a estatística remontava às lições universitárias de Conring, intituladas Notitia Rerum Publicarum e Notitia Statuum Germaniae, em um período contemporâneo a Graunt e Petty. Portanto, a raiz inglesa e a alemã se desenvolveram contemporaneamente. Somente o trabalho pioneiro de Conring, que escrevia preferencialmente em latim, ficou por muito tempo 
desconhecido, e ainda na atualidade muitos historiadores não o reconhecem como origem da estatística universitária alemã. Achenwall havia sido o primeiro a definir seu objeto de estudo como próprio de uma ciência autônoma (Cullen, 1975), e em fazer-lhe uma apresentação sistemática em língua alemã (Lazarsfeld, 1961), dando-lhe o nome de Statistik.

Uma segunda expressão foi a enumeração sistemática (por exemplo, da população) a cargo de entidades públicas, que começou na Prússia na primeira metade do século XVIII, e havia sido proposta às autoridades por Leibniz. Ele tinha um vívido interesse pelas questões estatísticas, particularmente aquelas relativas às enfermidades, à mortalidade e à população em geral, e propôs um sistema de 56 categorias para avaliar o Estado (incluindo o sexo e o status social dos habitantes, a mortalidade infantil e a quantidade de mulheres em condição de contrair matrimônio etc.). A terceira manifestação, de tipo privado e estilo próximo ao da aritmética política inglesa constitui-se a partir dos estudos populacionais de Süssmilch sobre nascimentos e mortes (Hacking, 1990).

Como já indicado, a manifestação que penetrou nos círculos intelectuais ingleses, em fins do século XVIII, foi a Universitätsstatistik. Aparentemente, o trabalho de Achenwall havia criado fama não somente por estar escrito em alemão (aspecto fundamental em um momento em que o latim perdia força, mesmo nas instituições acadêmicas), mas também pelo ambiente institucional em que foi desenvolvido na Universidade de Göttingen, fundada em 1737. Ali se constituiu uma escola famosa na Europa, na qual se refinaram as ideias de Conring e se conceberam novos instrumentos metodológicos. Um dos interesses fundamentais consistia na apresentação comparada da informação referente aos diversos estados alemães ${ }^{11}$ mediante um esquema de duas dimensões: na horizontal se colocavam os Estados a comparar, e na vertical as categorias relevantes para tal comparação. Originalmente as células definidas pelo cruzamento das dimensões se preenchiam com expressões verbais. Gradualmente se começou a fazer uso de expressões numéricas, uma consequência inevitável de tal esquematização ao menos porque os números ocupavam menos espaço (Lazarsfeld, 1961). A tendência à apresentação numérica favoreceu, por sua vez, a apreciação daqueles temas mais afins à quantificação, antecipando a matriz moderna de dados, que não poucos (ver, por exemplo, Marradi, 1989; 1996) consideram o instrumento intelectual e operativo mais importante na investigação social de tipo padrão.

Em seguida à tradução do livro de von Bielfeld The elements of universal erudition, containing an analytical abridgement of the sciences, polite arts, and belles lettres, realizada por Hooper, o termo não foi usado em inglês até 1787, ano no qual se traduziu outra obra alemã, um ensaio de von Zimmermann, intitulado A political survey of Europe, in sixteen tables; illustrated with observations on the Wealth and Commerce, the Government, Finances, Military Sate, and Religions 
of the several countries. No entanto, a versão anglicanizada do termo (com um significado um pouco diverso do original alemão) não apareceu até 1791, com a publicação do primeiro dos 21 volumes de Statitiscal account of Scotland, uma compilação a cargo de Sir John Sinclair, figura central de uma rede de pastores presbiterianos cujo trabalho coletivo tornou possível esta obra monumental (Cullen, 1975; Porter, 1986). Sinclair concebeu a investigação estatística como aquela que faz "referência à população, às circunstâncias políticas, à produção e outros aspectos do Estado" (apud Cullen, 1975: 10). Segundo Porter (1986), Sinclair adotou deliberadamente o termo "estatística", mas simultaneamente fez notar que seu projeto diferia do alemão; enquanto as pesquisas alemãs chamadas statistik se interessavam pelas questões do Estado, aquelas propostas por Sinclair buscavam determinar o quantum de felicidade do povo e os meios para seu progresso. No entanto, a edição de 1797 da Encyclopaedia Britannica definia o vocábulo como "uma palavra introduzida recentemente para expressar um panorama ou quadro geral de um reino, condado ou paróquia" (Mackenzie, 1981: 7) que é a acepção alemã.

O encontro da political arithmetic inglesa e da Universitätsstatistik alemã, em fins do século XVIII, gerou uma controvérsia acerca do estatuto científico e da utilidade da disciplina. A batalha conceitual ${ }^{12}$ foi vencida pelos aritméticos políticos, inclusive na Alemanha. Com efeito, Knies (1850) conclui que se o termo "estatística" foi introduzido por Achenwall, deveria usar-se no sentido da aritmética política. O objeto da antiga tradição alemã foi considerado a partir daí mais um tema da ciência política (Lazarsfeld, 1961) que deveria denominar-se Staatskunde (Hacking, 1990), termo que segundo Westergaard (1932) se aplicava aos estudos de Conring antes de Achenwall rebatizá-los como Statistik.

Não deveria surpreender, por conseguinte, que nos 30 ou 40 anos posteriores a Sinclair, se começara progressivamente a ligar a estatística com algum elemento de quantificação. ${ }^{13}$ Não obstante, uma acepção exclusivamente quantitativa ainda não se impusera, apesar do recurso da quantificação, porque o uso de técnica de análise matemática, além de fins atuariais, estava relativamente pouco difundido (Cullen, 1975).

A explosão das estatísticas numéricas ocorreu na Inglaterra na primeira metade do século XIX com a aparição do "movimento estatístico" (statistical movement), típico das primeiras décadas do reinado de Vitória e com a institucionalização das repartições governamentais especializadas. Em 1832 se fundou o Departamento de Estatística do Ministério do Comércio (Board of Trade), um escritório centralizado capaz de gerar estatísticas que sustentassem as reformas promovidas por importantes atores políticos e sociais da época. Por outro lado, este departamento deveria satisfazer a demanda de informação precisa e confiável acerca do que ocorria no interior do país, especialmente no que dizia respeito à produção industrial e ao comércio. Em 
1836 se instituiu o Escritório Geral de Registro (General Register Office), encarregado da sistematização dos dados referentes a nascimentos, mortes e casamentos (Cullen, 1975).

Nesta época se formaram também as associações dedicadas exclusivamente à estatística. A primeira se organizou em Manchester, em 1883. Pouco antes fora fundada a seção de estatística da British Association for the Advancedment of Science, graças às influentes presenças de Malthus e Quetelet na reunião realizada em Cambridge. No entanto, nem todos aprovavam a existência de uma seção desse tipo no interior da Association (Porter, 1986). Seus fundadores foram também membros ativos do núcleo inicial da Statistical Society of London, criada em março de 1834, e transformada em Royal Statistical Society em 1886: "Embora se contasse com alguns matemáticos entre seus membros originais, havia muitos mais economistas, políticos e peers ${ }^{14}$, agentes do governo e médicos: seu objeto era a produção de informação útil acerca da sociedade, não o desenvolvimento de métodos matemáticos" (Abrams, 1968: 14).

Formaram-se também instituições análogas em outras cidades importantes, em particular em Glasgow, que teve duas associações ao mesmo tempo. O desejo de entender as transformações sociais da época, e estabelecer uma base científica para as políticas sociais, era, sem dúvida, a característica do movimento estatístico dos primeiros decênios do reinado de Vitória (Porter, 1986).

Um dos temas de maior interesse consistia nas "estatísticas morais", relativas à educação, à criminalidade, e, em menor medida, à religião. Seus mentores eram em geral contrários à intervenção do Estado na economia, mas favoráveis a sua decisiva participação nas questões sanitária e educativa. Buscavam-se as causas da "degeneração moral", do aumento do crime e da instabilidade social, problemas que preocupavam quase obsessivamente os membros das sociedades estatísticas. A pesquisa que propunham devia servir como sustentação empírica das reformas que defendiam (Porter, 1986). Não obstante, resulta evidente que estes fins explícitos escondiam também "uma latente função de controle social [...] dada a ameaça potencial à ordem pública que [para eles] constituíam os amplos estratos sociais que vivam em condições miseráveis" (Pitrone, 1996: 19).

A urbanização, mais que a industrialização, dominava a mente dos statists ${ }^{15}$, que estavam convencidos de que o caráter e os costumes da população dependiam do ambiente urbano. Isto conduziu ao destaque das condições de vida da classe operária urbana, assunto no qual a Sociedade de Manchester foi pioneira. As Sociedades queriam promover uma classe operária virtuosa. Segundo suas pesquisas, os camponeses se caracterizavam pela sobriedade, frugalidade e laboriosidade. Ao contrário, nas cidades a situação era alarmante. As reformas sanitárias e educativas eram consideradas dois 
modos de enfrentar a decadência moral e a agitação política das classes operárias urbanas (Cullen, 1975).

O descontentamento popular era muito elevado nos anos 1930 e 1940 do século XIX. Através da melhoria da situação social, as reformas buscavam, na realidade - como já indicado -, erradicar a ameaça representada pelas forças anarquistas e socialistas. Para os membros das sociedades estatísticas a educação implicava uma combinação de instrução física, moral e intelectual; seu propósito era, em essência, converter uma classe ao sistema de valores de outra. A segunda reforma dizia respeito à saúde pública; pensava-se que as condições do ambiente físico tinham efeitos degradantes.

A prosperidade alcançada em meados da era vitoriana e a consequente relativa tranquilidade social desestimularam as teorias baseadas na urgência das reformas sociais, típicas do movimento estatístico. As sociedades provinciais - com a exceção de Manchester - desapareceram, e o movimento, com suas características distintivas, perdeu progressivamente o ímpeto. Aproximadamente a partir de 1850 , os temas tratados nas instituições restantes, em particular nas de Londres, se ampliaram, os interesses se diversificaram e começou a se registrar maior variedade de opiniões; houve um notável aumento das pesquisas econômicas (Cullen, 1975).

A coleta e compilação de dados numéricos estavam estabelecidas na Inglaterra por volta de 1850 . Porém, o tratamento matemático não era sofisticado e o termo "estatística" não tinha ainda a conotação que tem hoje. Como afirma Mackenzie (1981: 8) "na Inglaterra de meados do século XIX não havia uma tradição de teoria estatística". Por conseguinte, o movimento das primeiras décadas do reinado de Vitória não deveria ser considerado um precursor da moderna disciplina. Este movimento não deixou uma tradição de teoria estatística, e a coleta de informação quantitativa estava totalmente separada dos desenvolvimentos da teoria matemática das probabilidades (Mackenzie, 1981: 8).

Desde o nascimento da Statistical Society of London até 1850, somente $2 \%$ das memórias apresentadas tratava de questões vinculadas aos métodos estatísticos. Na introdução ao primeiro número do Journal, publicado em 1838, se definia a estatística enfatizando a importância da coleta de dados sociais e políticos, e menosprezando as questões metodológicas e de análise de dados: "A Ciência da Estatística [...] não discute causas [...] Somente busca coletar, organizar e comparar aquela classe de fatos que por si mesmos formam a base das conclusões corretas em matéria de governo social e político" (apud Porter, 1986: 35-36).

Segundo a concepção dominante, os dados "crus", sem “opiniões", constituíam a característica essencial da ciência e o fundamento da estatística. A primeira regra da Statistical Society era excluir os pareceres. William Farr, em nome da Sociedade, escreveu a Florence Nightingale, que estava preocupada com falta de análises em uma contribuição que então preparava para a 
revista: "não queremos impressões, somente fatos" (apud Porter, 1986: 36). E estes se apresentavam em forma quantitativa porque os números representavam os "verdadeiros fatos".

No entanto, nem todos estavam de acordo. Em 1838, Robertson afirmou que "Nenhuma forma de registro e organização de dados pode constituir por si só uma ciência [...] A estatística deve se entender como um método, um modo de organizar os fatos que pertencem às várias ciências" (apud Porter, 1986: 40). A transição a partir do movimento estatístico original, implicou, portanto, o início da decadência de sua concepção clássica da estatística e o tímido surgimento de outra ligada à ideia de método. Como afirma Cullen (1975), neste período de transição a Statistical Society não era ainda capaz de decidir se o objetivo principal da estatística eram os fatos ou o método; e já em 1860 um fellow, Fox, refletindo sobre os recentes desenvolvimentos da disciplina no continente, escrevia que a mesma deveria se considerar como um ramo da matemática.

Com efeito, a aplicação da matemática na investigação empírica começava a se manifestar nos países francófonos da Europa continental. Isto não deveria surpreender, dado que a teoria das probabilidades pertenceu inicialmente à tradição intelectual francesa. Esta perspectiva, na qual se combinava a teoria matemática com a ideia instrumental de um método aplicável às distintas ciências empíricas, se consolidou lentamente na Grã-Bretanha no período entre o fim do século XIX e o início do século XX. A assimilação da teoria continental das probabilidades, e sua aplicação à investigação dos fenômenos humanos contribuiu para produzir uma mudança radical de rumo, dando origem à teoria estatística moderna.

\section{TEORIA MATEMÁTICA DAS PROBABILIDADES E PESOUISA EMPÍRICA: PARA UMA REDEFINIÇÃO DA ESTATÍSTICA}

O exame da teoria das probabilidades e sua aplicação à pesquisa empírica (no contexto de um artigo que trata das origens da estatística) poderia iniciar-se com um fato histórico casual relativo ao surgimento, na França, desta tradição intelectual - o estudo das probabilidades - contemporaneamente à aparição do pensamento estatístico inglês, na forma da aritmética política e do alemão, manifestado na Universitätsstatistik.

As origens da teoria das probabilidades podem remontar a meados do século XVII, com o trabalho pioneiro de Fermat e Pascal. No seu início, a teoria não pretendia desafiar a concepção da natureza então dominante, que Hacking (1990: cap. 2) chama "doutrina da necessidade", ${ }^{16}$ e se limitava a aplicações abstratas no campo dos jogos aleatórios (Stigler, 1999), distante de qualquer consideração sobre as características da realidade. 
Se a estatística inglesa pode apresentar-se como uma aplicação dos princípios de Bacon aos problemas políticos e sociais e, por conseguinte, como uma manifestação da orientação empirista da filosofia e da cultura inglesas (Mitchell, 1973: 147), a teoria das probabilidades pode se enquadrar na tradição racionalista francesa, como uma manifestação da orientação abstrata, matemático-dedutiva, de fundo cartesiano. Paradoxalmente, ainda que baseada na tradição da racionalidade, a dialética das probabilidades desgastaria gradualmente alguns dos princípios sobre os quais se fundava a racionalidade moderna, em especial a ideia de certeza.

Embora inicialmente relacionada à especulação abstrata sobre jogos aleatórios, logo se descobriu que a teoria das probabilidades era capaz de fornecer instrumentos úteis para a pesquisa científica. Galileu já havia declarado que a medição e o cálculo eram cruciais no trabalho científico, único modo para entender uma realidade que Deus havia escrito na linguagem da matemática. Paralelamente, Descartes havia promovido a matemática como a chave do pensamento científico organizado. Não obstante, a medição ficou confinada por muito tempo à astronomia e outras disciplinas clássicas. Não deveria surpreender, por conseguinte, que a teoria das probabilidades encontrara suas primeiras aplicações neste campo, no qual a medição estava já bem sedimentada desde os tempos de Galileu. Como assevera Stigler (1999), muitas das mais relevantes contribuições à estatística moderna surgiram da consideração de problemas científicos concretos, e o caso da medição em astronomia em um exemplo típico.

De fato, este problema favoreceu o aperfeiçoamento dos instrumentos conceituais e heurísticos nos quais se fundamenta a teoria dos erros, que se "desenvolveu nos séculos XVII e XVIII como um apêndice [...] da astronomia" (MacKenzie, 1981: 56). Os astrônomos "deveriam reconhecer que era impossível medir uma coisa com completa exatidão". No entanto, o pesquisador podia aproveitar a possibilidade de repetir suas medições aos efeitos para aumentar a precisão. O objetivo da teoria dos erros era justamente este: "reduzir ao máximo possível o erro em uma quantidade dada, e dar uma estimação confiável de [seu] valor" (MacKenzie, 1981: 56). As aplicações da teoria dos erros em astronomia se estabeleciam em dois instrumentos de excepcional importância, ainda hoje fundamentais na investigação científica: a distribuição normal e o método dos mínimos quadrados.

Em 1733, De Moivre ${ }^{17}$ introduziu na teoria das probabilidades a função da curva normal, então conhecida como lei dos erros. ${ }^{18}$ Pela primeira vez era possível aplicar a teoria das probabilidades a um número indefinidamente grande de eventos independentes (Porter, 1986). A inovação de De Moivre, entretanto, teve pouca influência até os anos 1970 do século XVIII, quando Laplace começou a escrever sobre teoria das probabilidades. Ele viu na curva normal um instrumento excelente cuja aplicabilidade ele estendeu à proba- 
bilidade a posteriori: com efeito, até a publicação de uma memória sua de 1774, a ideia da probabilidade estava bem mais confinada ao cálculo apriorístico do resultado de jogos aleatórios.

Laplace estava convencido de que as mais importantes questões da vida eram problemas de probabilidades, e, por conseguinte, suscetíveis à aplicação de suas teorias. Porém, ele estava igualmente convencido de que os eventos do mundo eram absolutamente determinados; o lugar para o azar e para a teoria das probabilidades se localizava no espaço existente entre aquele que é e o que o homem pode conhecer. Para ele a realidade escapa muitas vezes à possibilidade de entendimento da mente humana, e por isso a probabilidade é uma propriedade gnosiológica, não ontológica (Richards, 1997). Laplace repropõe o dogma da necessidade: todos os eventos, até mesmo aqueles que por serem insignificantes não parecem seguir as leis da natureza, são, na realidade, uma consequência necessária delas.

Outra contribuição importante na aplicação da lei dos erros está ligada ao nome de Fourier. Ele estava muito impressionado pela repetição indefinida de eventos que parecem fortuitos, e que, contudo, se considerados em conjunto, fazem desaparecer toda impressão de irregularidade. Fourier estava convencido da possibilidade de aplicar a lei dos erros a uma vasta gama de campos e objetos, todos caracterizados por uma unidade subjacente até então oculta, revelada graças à universalidade da curva dos erros (Porter, 1986).

O método dos mínimos quadrados tem uma história mais recente. Em 1805 Legendre anunciou um método geral para reduzir as múltiplas observações de um objeto - como uma estrela ou um planeta - embora o tenha apresentado sem uma justificativa probabilística. Esta foi a primeira comunicação efetiva do método, já que possivelmente Gauss - como ele mesmo declarou em várias ocasiões - o usava desde há quase dez anos, sem haver tido a oportunidade de fazê-lo em público. ${ }^{19}$

Em 1810, Laplace proveu uma derivação alternativa do método dos mínimos quadrados, e estabeleceu que os erros em astronomia, como nos estudos populacionais, deveriam distribuir-se segundo a lei dos erros (Porter, 1986). Como afirma MacKenzie (1981: 57): “Os teóricos dos erros mostraram que a melhor estimativa de uma quantidade [...] era geralmente a média das diversas medições, e que estas medições seguiam tipicamente a distribuição matemática que chamavam 'lei da frequência dos erros'”.

Os astrônomos e matemáticos do século XIX produziram uma enorme quantidade de artigos sobre o método dos mínimos quadrados. ${ }^{20}$ À morte de Laplace, em 1827, a teoria das probabilidades havia alcançado um alto nível. Até meados do século, o conhecimento das técnicas matemáticas das probabilidades estava muito difundido, acessível a qualquer um que tivesse conhecimentos de análise. A aplicação destas técnicas, especialmente do método dos mínimos quadrados, era rotina em astronomia e geodésia, porém sua 
difusão em outros campos era lenta (Stigler, 1999). Não deveria surpreender, por conseguinte, que a extensão destes métodos ao campo dos fenômenos humanos se deva a uma figura com profundos conhecimentos astronômicos - Adolphe Quetelet - e ligada à cultura científica francófona, ${ }^{21}$ não somente por sua posição privilegiada como berço da teoria das probabilidades, mas também pelo status que a estatística havia adquirido na França de princípios do século XIX.

Realmente, não são poucos os que situam na França o centro do grande entusiasmo estatístico das primeiras décadas do século (ver, por exemplo, Hacking, 1990), que poucos anos depois encontraria eco no movimento estatístico vitoriano. A paixão pela informação quantitativa era já forte nos tempos do Consulado e do Império, em particular no âmbito da saúde pública. Por outro lado, como seus colegas ingleses, os estatísticos franceses eram burgueses que procuravam substituir "o longo reino da opinião, os interesses de partido e a confusão política por um núcleo de fatos sociais bem estabelecidos e de verdades rigorosamente deduzidas" (Coleman, 1982: 275).

As leis das probabilidades, aplicadas com êxito inicialmente na astronomia, começaram lentamente a ser exportadas a outros campos. Em um período em que as ciências físicas ainda não necessitavam das probabilidades, o "descobrimento" de leis estatísticas nas questões humanas caracterizadas pela regularidade era uma consequência previsível. A "lei dos grandes números”, proposta por Poisson em 1835, proveu fundamentos ainda melhores para aplicar a matemática das probabilidades aos problemas sociais (Hacking, 1990).

Quetelet seria, em grande medida, o responsável por esta mudança de rumo na história da estatística, reforçando a tendência à quantificação em diversas áreas além da astronomia, e ao mesmo tempo concedendo especial atenção aos métodos para o tratamento de dados quantitativos (Lazarsfeld, 1961). Profundamente influenciado pelos trabalhos de Laplace e de Fourier na teoria das probabilidades, Quetelet se convenceu, por volta de 1830, da possibilidade de tratar as questões humanas aplicando os métodos já comuns em astronomia, indo além da mera coleta e classificação dos dados. Segundo Lazarsfeld (1961: 295): "Esta combinação da matemática abstrata e da realidade social proveu a convergência ideal para as duas linhas nas quais se havia desenvolvido a mente de Quetelet".

Inicialmente ele tentou aplicar as noções probabilísticas à medição do corpo humano - um interesse ligado ao seu desejo juvenil de ser escultor - e em seguida publicou um trabalho sobre a aplicação das probabilidades nas "ciências políticas e morais".

Em 1844 Quetelet anunciou que a lei dos erros se aplicava também à distribuição das características humanas. Para ele, as leis estatísticas se manifestavam como regularidades expressas em termos de frequências. O conceito central era o de normalidade, e esta se representava mediante o valor 
médio da distribuição. O homem médio (homme moyen) era a base da comunidade, e tomava seu significado do mesmo. Quetelet estava consciente de que a média não era suficiente para comparar distribuições (Stigler, 1999), não obstante não se interessou pela variabilidade dos fenômenos humanos. Sua assimilação da normalidade com aquilo que é justo, correto, bom - que se reencontrará mais adiante em Durkheim - tenderá a conceber a variabilidade como uma manifestação patológica. Somente uma reinterpretação do termo - quando normalidade se tornou mediocridade - permitirá no Reino Unido de fins do século XIX recuperar a variabilidade como um problema científico relevante, abrindo, deste modo, a porta a uma nova revolução na história da estatística.

Por volta de 1830-1840, os ingleses entraram em contato com os desenvolvimentos científicos continentais, e tiveram que enfrentar o desafio de assimilar a teoria das probabilidades em uma cultura na qual os limites entre ciência e religião não eram ainda claros (Richards, 1997). A teologia natural de inspiração anglicana dominava os ambientes universitários de Cambridge e Oxford, e intelectuais influentes - por exemplo, Whewell - se opunham à orientação dos "matemáticos continentais", especialmente a de Laplace.

Foi Augustus de Morgan quem apresentou a teoria de Laplace ao público inglês em dois trabalhos fundamentais: Theory of probabilities, publicado em 1838 na Encyclopaedia Metropolitana, e um ensaio sobre as probabilidades e sua aplicação aos seguros, publicado na Cabinet Cyclopedia. Para não desafiar as ideias dominantes da teologia natural, De Morgan ocupou-se, acompanhado a Laplace, em colocar as incertezas que a teoria matematizava na mente humana, e não no mundo exterior (Richards, 1997). De todo modo, ficou claro que a teoria das probabilidades tinha importantes aplicações práticas, em especial na astronomia e no campo dos seguros, tema caro à estatística inglesa desde o século XVII.

Em 1850, o influente astrônomo Herschel chamou a atenção dos cientistas ingleses com relação às ideias de Quetelet sobre a aplicação das probabilidades aos dados sociais (Lazarsfeld, 1961). Por outro lado, Quetelet já era conhecido nos círculos acadêmicos da Inglaterra. Nos anos 1930 havia tido um papel decisivo na criação da seção de estatística da Association for the Advancement of Science, e em 1844 havia apresentado, em um encontro de estatísticos realizado em Plymouth, um grande inventário de temas (meteorologia, física, química, botânica, zoologia, além das questões humanas) que a seu ver podiam ser estudados com os novos métodos estatísticos.

Contudo, os instrumentos conceituais das probabilidades, e em particular a teoria dos erros, seguiram sendo uma especialidade continental. Dos quase quinhentos ensaios relativos à lei dos erros e ao método dos mínimos quadrados, listados por Merriman em 1977, somente 14\% haviam sido publi- 
cados na Inglaterra (MacKenzie, 1981). Um exemplo é o de Stanley Jevons, que havia estudado a teoria das probabilidades com De Morgan em Londres e defendia sua utilidade nas ciências sociais, assim como a matematização da economia. Não obstante, não fez nenhuma tentativa de aproveitar os instrumentos probabilísticos para a quantificação da incerteza nessas disciplinas.

A mudança de atitude dos ingleses a respeito das probabilidades e o seu uso prático ocorreu no último quarto do século XIX, em um ambiente no qual o evolucionismo darwinista estava criando condições mais favoráveis ao desenvolvimento de uma ciência não determinística. Foi justamente um primo de Darwin, Frances Galton, o maior responsável pela revolução que conduziu à teoria estatística moderna.

A orientação evolucionista levou Galton a se interessar pelo problema da herança dos caracteres humanos. Na procura de instrumentos estatísticos adequados, ele entrou em contato com a teoria dos erros que Quetelet já havia aplicado com êxito às questões humanas (MacKenzie, 1981). Porém, Galton não se conformava com a mera aplicação universal da lei dos erros. Opunha-se à sua interpretação da normalidade: as divergências em relação à média não eram necessariamente um defeito. Como reformista social de tendência eugênica, interessava-lhe o melhoramento da raça, e por isso, a difusão das características excepcionais que Quetelet considerava desviadas. O homme moyen não era o modelo ideal; era um medíocre cujos caracteres deviam ser melhorados na descendência.

A valorização do conceito de variabilidade era uma consequência inevitável. Galton foi o primeiro a usar os métodos de análise dos erros para tratar a variação empírica; entretanto, para este fim, a inadequação técnica da teoria dos erros começou a se tornar evidente: "Para os teóricos dos erros a variabilidade ('erro') era algo a se eliminar, ou ao menos a se controlar e medir. Os objetivos dos teóricos dos erros eram, portanto, contrários ao tratamento da variabilidade como um fenômeno de valor em si mesmo" (MacKenzie, 1981: 58).

Estudar a variabilidade exigia novos instrumentos conceituais e operativos. A estatística moderna, enquanto disciplina autônoma orientada para a análise quantitativa de dados, estava nascendo. Em fins do século XIX, quando a ideia segundo a qual todos os eventos do universo estavam determinados por uma lei natural necessária perdia força (Hacking, 1990), os novos conceitos de regressão e correlação (e seus respectivos instrumentos) permitirão analisar a variabilidades dos fenômenos e suas relações. A ciência, como pretendia Galileu, seguiria se orientado pela busca de relações entre propriedades; porém estas não seriam consideradas necessárias nem imutáveis. 


\section{VARIABILIDADE E CORRELAÇÃO NA ORIGEM DA MODERNA TEORIA ESTATÍSTICA: UMA VERDADEIRA REVOLUÇÃO}

Em certo sentido, a mudança de interesse do erro para a variabilidade vis lumbra-se na interpretação da frequência típica do pensamento de Quetelet. A função provável dos erros, à qual Galton se referiu poeticamente como "lei suprema da irracionalidade", era um dos focos da atenção de Quetelet. Desde a sua introdução, em meados do século XVII, esta curva sofreu um processo de gradual mudança conceitual em suas aplicações na pesquisa empírica: da distribuição dos erros de medição em astronomia às divergências em relação a um homem médio idealizado, e então para a variabilidade genuína dos fenômenos naturais e sociais. Segundo Porter (1986: 91), a reinterpretação da curva normal como "a lei da variação genuína, ao invés do mero erro, foi o resultado central do pensamento estatístico do século XIX". Isto tornou possível o desenvolvimento das modernas técnicas de análise estatística, começando pela regressão e pela correlação, cuja invenção Stigler (1999: 6) considera "um dos maiores eventos na história da ciência".

A quase simultânea aparição do livro Natural inheritance, de Galton (1889), e do método da correlação marca o início do período moderno da estatística. A correlação, como instrumento, prometia ser útil em todos os campos científicos, especialmente naqueles em que resultava problemático estabelecer diretrizes de casualidade. Porém, nos tempos de Galton a teoria estatística como disciplina científica era efetivamente inexistente na Inglaterra: não se ensinava como curso universitário, ${ }^{22}$ não tinha uma base institucional e não se publicava nenhuma revista especializada no assunto. $^{23}$

Galton estava consciente disso, e logo se deu conta de que a regressão e a correlação poderiam ser o ponto de partida de uma nova disciplina científica; mas para isto deviam se organizar as contribuições dispersas e apresentar o conhecimento de modo sistemático. Em sua biografia, escrita por Karl Pearson (1914-1930), se reproduz uma carta do período: "O momento está maduro para que um matemático competente" reordene o material da estatística: "Ele haverá fundado uma nova ciência".

A difusão dos nascentes conceitos de regressão e correlação, em torno de 1890, começou a chamar a atenção de estatísticos notáveis, como Edgeworth, e de promissores jovens cientistas, como Weldon e Pearson. O sonho de Galton de uma nova disciplina tomava corpo.

Até 1900, o caráter intelectual da estatística resultou completamente transformado graças ao trabalho de Galton, Edgeworth e Pearson (Porter, 1986). De uma disciplina limitada ao estudo quantitativo do homem e da sociedade, estava se transformando em uma disciplina capaz de prover instrumentos de análise a uma vasta gama de ciências. Já em seus primeiros cursos de 
estatística avançada, ministrados na Universidade de Londres a partir de meados da década de 1890, Karl Pearson ensinava que

estatística é [...] um termo utilizados para medições conjuntas de qualquer fato, seja social, físico ou biológico. A teoria pura da estatística é uma ramificação da matemática que se ocupa da compilação, representação e tratamento [destes] conjuntos numéricos - independentemente dos fatos que tais números representem. A estatística aplicada [em resumo] é o uso dos métodos da estatística pura para classes especiais de fatos - observações biológicas, físicas ou políticas (Yule, 1938: 200). ${ }^{24}$

Nas últimas décadas do período vitoriano a ciência estava se profissionalizando velozmente, e os cientistas seguiam linhas de pesquisa cada vez mais especializadas (Lightman, 1997). A ruptura do contexto intelectual comum assegurado pela teologia natural, consequência inevitável do evolucionismo darwinista e do desenvolvimento da teoria das probabilidades, favoreceu a especialização e profissionalização da ciência (Young, 1985), assim como a institucionalização de diversas disciplinas. Mas, assim como afirma MacKenzie (1981), são muitos os aspectos a se lembrar antes de se falar do surgimento de uma disciplina. Necessita-se, entre outras coisas, de uma rede de cientistas interessados no mesmo tipo de problemas; um conjunto de instrumentos de análise e de enfoques mais ou menos compartilhados; meios de comunicação - formais e informais - entre os peritos; mecanismos de recrutamento e de ensino, com uma forma estável e uma base institucional; recursos financeiros e de outros tipos. A tendência à especialização e à profissionalização da ciência, em resumo, resultou fundamental na institucionalização da estatística como disciplina autônoma.

Neste processo a figura central foi Karl Pearson: combinando sua capacidade matemática com os interesses de pesquisa promovidos por Galton, e manifestando um entusiasmo pela institucionalização que Porter (1986) acertadamente qualifica como próprio de uma "mentalidade acadêmica empreendedora", conseguiu estabelecer - intelectual e socialmente - a estatística como uma nova disciplina.

De sua colaboração com Weldon, iniciada em 1892, teve origem a Escola Biométrica. Desde 1894, quando Pearson começou a ministrar o curso de estatística avançada, até os anos vinte do século XX - quando Fisher estabeleceu um centro de pesquisa na estação experimental de Rothamsted - a Escola Biométrica foi a única instituição britânica dedicada à teoria estatística (MacKenzie, 1981). Já na primeira década de sua criação, em torno de metade de todos os artigos ingleses sobre teoria estatística se produziam neste ambiente institucional. Biometrika, a revista da Escola, foi por muitos anos a publicação mais importante de teoria estatística da Inglaterra, e continua sendo uma revista de prestígio internacional na disciplina. Além disso, a Escola foi por muitos anos o mais importante centro de ensino na matéria, atraindo estudantes que logo adquiririam notoriedade e posições de grande 
relevância institucional e acadêmica (Norton, 1978). Não deveria surpreender a afirmação de Levine (1996), para quem a estatística como disciplina científica foi modelada por Karl Pearson, que lhe deu forma e direção, dominando a cena mundial da especialidade desde a metade dos anos noventa do século XIX até a Primeira Guerra Mundial.

Entretanto, este ambiente acadêmico, ainda que sendo o mais importante, não era completamente hegemônico. ${ }^{25}$ À medida que se consolidava, a disciplina começava a ser praticada também em outras instituições. ${ }^{26}$ Os interesses intelectuais que haviam dado o primeiro impulso para o desenvolvimento das técnicas de regressão e correlação se diversificaram; e os instrumentos da Escola Biométrica, concebidos para o tratamento de questões eugênicas e biológicas, demonstraram sua utilidade em outras disciplinas (MacKenzie, 1981).

Com o passar do tempo, a articulação de estatística, biometria e eugenia, típica do enfoque de Galton e de Pearson perdeu seu impulso. A disciplina estava amadurecendo, e sua consolidação erodia o poder quase monopolista de Pearson. Novos líderes intelectuais e institucionais, particularmente Fisher, ganhavam espaço no mundo já menos restrito da estatística matemática.

Nos anos 1930 a situação era radicalmente distinta se comparada com aquela em que Pearson havia começado a trabalhar: havia um grupo de pesquisadores ativos dedicados exclusivamente à disciplina; na University College de Londres havia se criado uma nova área orientada à didática e pesquisa em teoria estatística; e na estação de pesquisa agrícola de Rothamsted Fisher havia criado um segundo centro especializado. A revista Biometrika seguia publicando importantes contribuições teóricas, e o Journal da Royal Statistical Society dava cada vez mais espaço a artigos deste tipo.

O trabalho essencial para a constituição da teoria estatística como conjunto de instrumentos de análise quantitativo aplicáveis à pesquisa empírica estava, em grande parte, realizado. Neste período, um artigo de Egon Pearson (filho de Karl) e Neyman (1933) sobre os testes de hipótese mais eficazes, abria o caminho à estatística indutiva, ${ }^{27}$ provavelmente a escola mais influente e prolífica da estatística do século XX. Estes desenvolvimentos alertaram a um já idoso Karl Pearson, que pressagiou, com amargura, o advento de uma estatística matemática pura, que, convertida em um fim em si mesma, se afastaria de sua função instrumental a serviço dos fins cognitivos da pesquisa empírica. 
DE OBJETO A MÉTODO: NOTAS HISTÓRICAS SOBRE ESTATÍSTICA E PESQUISA SOCIAL

262

Juan Ignacio Piovani é doutor em Metodologia das Ciências Sociais pela Università di Roma La Sapienza. É professor titular de Metodologia, pesquisador e coordenador do Programa de Mestrado e Doutorado em Ciências Sociais da Faculdade de Humanidades e Ciências da Educação da Universidade Nacional de La Plata. Pesquisador do Consejo Nacional de Investigaciones Cientificas y Técnicas (CONICET). Publicou Alle origini della statistica moderna. La scuola inglese di fine ottocento (2006) e, com Alberto Marradi e Nelida Archenti, Metodología de las ciencias sociales (2007). 


\section{NOTAS}

1 Hacking retira esta expressão de Crombie (1983). Outros preferem recorrer ao conceito de paradigma, que desde sua introdução nos anos de 1960 passou a ocupar um lugar fundamental quando se trata de entender que as ideias científicas compartilhadas em um momento determinado - e consideradas como dadas pela maior parte dos cientistas - são na realidade construções sociais complexas.

2 Obviamente, falar de êxito não significa, neste caso, valorizar as benesses ou a pertinência deste modo de raciocínio; significa somente reconhecer sua hegemonia e sua onipresença nas maneiras atuais de conceber a realidade e justificar um discurso sobre ela.

3 Discutiu-se muito nos ambientes acadêmicos ingleses acerca da autoria da obra citada. Uma apresentação detalhada deste debate se encontra em Cullen (1975). Muitos estudiosos acreditam que Graunt foi o autor das Observations, enquanto Petty teria sido o autor das conclusões e do quadro geral. Cullen sustenta que, de toda forma, Petty foi o artífice das ideias que geraram o estudo estatístico da sociedade.

4 Entre as conclusões mais importantes de Graunt, Hull (1899) menciona a regularidade dos fenômenos sociais; o nascimento de mais homens que mulheres; o equilíbrio aproximado na quantidade homens e mulheres na sociedade; a alta taxa de mortalidade nos primeiros anos de vida; a maior taxa de mortalidade nos ambientes urbanos em relação aos rurais.

5 Cullen (1975) afirma que o trabalho de Graunt mostra grandes dotes metodológicos. Sublinha, por exemplo, que antes de analisar estatisticamente um dado, o autor se ocupa seriamente de sua confiabilidade.

6 Petty usa a palavra inglesa antiga empiricks, cujo significado não seria equivalente ao do termo moderno empiricist (empirista). Considerada em seu contexto, empirick faz referencia à pessoa que trabalha baseando-se em sua experiência, e não a partir do conhecimento científico.

7 Lazarsfeld indica que estas são as explicações "convencionais". No que diz respeito à quantificação e a medição, 
por exemplo, nem todos estão de acordo. Há um amplo consenso em atribuir a Galileu o impulso para a quantificação científica, já que para entender a realidade era necessário medir e calcular. Não obstante, a medição ficou por muito tempo confinada à astronomia, à geodésia, à mecânica e outras disciplinas clássicas. Teve um lugar central na física e na química pelo menos até 1840 (Kuhn, 1961; Hacking, 1990).

8 Observe-se a importância do projeto eugenista para o desenvolvimento do que, como assinalado na introdução, MacKenzie (1981) chama "teoria estatística" e Porter (1986) chama "estatística matemática". Alguns de seus principais expoentes - Galton, Pearson, Fisher - compartilham a ideia de levar adiante um projeto eugenista (Mackenzie, 1981).

9 Definição de von Bielefeld, traduzida para o inglês por Hooper em 1770.

10 Para Westergaard, esta disciplina poderia remontar a Aristóteles.

$11 \mathrm{Na}$ época, a Alemanha não era ainda um Estado unificado.

12 Sobre a importância das batalhas conceituais e terminológicas no mundo científico, ver Toulmin (1972) e Marradi (1987).

13 Já em 1801 Playfair havia sugerido que o termo "estatística" devia conotar alguma forma de quantificação, mas não teve grande influência em seus contemporâneos. Nota-se que não foi citado por outro autor inglês até Jevons, em 1879 (Cullen, 1975).

14 Membros da Câmara dos Lordes.

15 Depois da introdução do termo statistics, as pessoas dedicadas ao trabalho com dados numéricos começaram a ser conhecidas na Inglaterra como statists. O termo statistician (estatístico ou estadígrafo) remonta, no entanto, a fins do século XIX.

16 Descartes foi seu primeiro defensor; também Kant, em seus escritos éticos e metafísicos, sustentava uma ideia análoga. Hume, apesar de ser um filósofo crítico com respeito à ideia de casualidade, escreveu em Enquiry concerning human understanding (1748) que nada existe sem uma causa para sua existência. Seu ceticismo se limita ao pla- 
no epistemológico, à possibilidade de conhecer as causas, porém não ao plano ontológico, isto é, a sua existência (Hacking 1990).

17 O livro de De Moivre, The doctrine of chances, foi publicado em 1718. A função da curva normal foi introduzida na segunda edição de 1733 .

18 O termo "normal" para se referir à lei dos erros surgiu na segunda metade do século XIX, quando esta começava a ser usada em outros contextos, além da astronomia (Stigler 1999). A distribuição normal também é conhecida como curva de Gauss, endossando a "lei da eponimia de Stigler", segundo a qual "nenhum descobrimento científico leva o nome de seu propulsor original" (Stigler, 1999: 7).

19 Esta é a conclusão das pacientes investigações de Stigler (1981; 1999) sobre a história da estatística.

20 Em 1877 Merriman listou 408 livros e memórias sobre a lei da frequência dos erros e o método dos mínimos quadrados (MacKenzie, 1981).

21 Quetelet era belga, porém estudou em Paris e foi muito influenciado pela cultura científica francesa.

22 Falando dos anos 1890, Yule (1938) afirma que um curso de teoria estatística simples e coerentemente organizado não podia então existir já que muitos dos elementos fundamentais da disciplina apenas começavam a se desenvolver.

23 Lembra-se que a Statistical Society of London, já convertida em Royal Statistical Society no momento da publicação de Natural inheritance, não estava comprometida com o desenvolvimento da disciplina como entendida na atualidade. Sua revista publicava muito ocasionalmente artigos dedicados ao método estatístico.

24 Para Karl Pearson, este aspecto aplicado da estatística era fundamental: ele era favorável a "reavivar a tradição de aplicar a ciência à vida prática" (Pearson, 1948: 48).

25 Os especialistas em teoria estatística que não trabalhavam na Escola Biométrica não estavam isolados, como nos tempos de Galton, nem eram irrelevantes. Muitos participavam nas discussões teóricas e técnicas da época, publicavam e ensinavam estatística em diversos âmbitos. 
Até mesmo Edgeworth, que provavelmente por sua personalidade não se sentia parte de escola alguma, tinha uma base institucional na Royal Statistical Society e contribuía com publicações e com a discussão do trabalho de outros. Na Royal Statistical Society estava surgindo um grupo relativamente articulado de pessoas interessadas na teoria estatística, guiado por Edgeworth mesmo, Yule e Hooker. O Journal começava a prestar mais atenção a estes temas. Alguns dos artigos publicados nele - em particular os de Yule - podem ser considerados contribuições decisivas para a teoria estatística moderna.

26 Um caso notável é o de Gosset, conhecido na estatística pelo desenvolvimento da distribuição $t$, chamada "student" pelo pseudônimo com o qual assinava seus artigos, Ele se uniu temporariamente à Escola Biométrica em 1906, mas trabalhava com problemas de estatística moderna em um ambiente totalmente distinto: era realmente empregado da cervejaria irlandesa Guinness. Apesar de seus contatos com a academia, decidiu seguir sua carreira no âmbito industrial, chegando a ser gerente da fábrica que a empresa inaugurou em Londres em 1935 (MacKenzie, 1981)

27 Stigler (1999), desafiando a opinião mais difundida, que localiza o nascimento da estatística moderna entre fins do século XIX e princípio do XX, a partir do trabalho de Galton e Pearson, afirma que a disciplina nasceu formalmente com a publicação do artigo citado, quando se deu origem ao desenvolvimento da estatística indutiva. 


\section{REFERÊNCIAS BIBLIOGRÁFICAS}

Abrams, Philip. (1968). The origins of British sociology. Chicago: Chicago University Press.

Coleman, William. (1982). Death is a social disease: public health and political economy in early industrial France. Madison: University of Wisconsin Press.

Cullen, Michael J. (1975). The statistical movement in Early Victorian Britain. Brighton: Harvester Press.

De Moivre, Abraham. (1718). The Doctrine of Chances: or, a method of calculating the probability of events in play. Londres: W. Pearson.

De Morgan, Augustus. (1838). Theory of probabilities. In: Encyclopaedia Metropolitana. Londres: Baldwin and Cradock (Vol. 2).

Galton, Francis. (1889). Natural inheritance. Londres: Macmillan.

Graunt, John. (1662). Natural and political observations on the bills of mortality. Londres: The Royal Society.

Hacking, Ian. (1990). The taming of chance. Londres: Cambridge University Press.

Hull, Charles H. (org.) (1899). The economic writings of sir William Petty together with the observations upon the bills of mortality, more probably by captain John Graunt. Londres: Cambridge University Press (2 vols.).

Hume, David. (1748). Philosophical essays concerning human understanding. Londres: Millar.

John, Vincenz. (1884). Geschichte der Statistik. Stuttgart: Ferdinand Encke.

Knies, Karl G. (1850). Die Statistik als Selbständige Wissenchaft. Kassel: Luckhardt.

Kuhn, Thomas. (1961). The function of measurement in modern physical science. Isis, 52, p. 161-193.

Laplace, Pierre-Simon. (1774). Mémoire sur la probabilité des causes par les événements. In: Memoires de l'Académie Royale des Sciences de Paris, 6, p. 621-656.

Lazarsfeld, Paul F. (1961). Notes on the history of quantification in sociology. Trends, sources and problems. Isis, 52/2, p. 277-333. 
Legendre, Adrien-Marie. (1805). Nouvelles methodes pour la détermination des orbites des comètes. Paris: Courcier.

Levine, George. (1996). Science and citizenship: Karl Pearson and the ethics of epistemology. Modernism/Modernity, 3/3, p. 137-143. Disponível em <http://muse.jhu.edu/journals/modernism-modernity/v003/3.3levine.html>. Acesso em 20 abr. 2013.

Lightman, Bernard. (1997). "The voices of nature": popularizing Victorian science. In: Lightman, Bernard (org.). Victorian science in context. Chicago: University of Chicago Press, p. 187-211.

Mackenzie, Donald A. (1981). Statistics in Britain, 1865-1930. The social construction of scientific knowledge. Edinburgh: Edinburgh University Press.

Marradi, Alberto. (1980). Concetti e metodi per la ricerca sociale. Florença: Giuntina.

Marradi, Alberto. (1987). Linguaggio scientifico o torre di Babele? Rivista Italiana di Scienza Politica, XVII/1, p. 135-156. Marradi, Alberto. (1997). Linee guida per l'analisi bivariata dei dati nelle scienze sociali. Milão: Franco Angeli.

Meitzen, August. (1886). Geschichte, Theorie und Technik der Statistik. Berlim: Hertz.

Mitchell, Geoffrey Duncan. (1973). Storia della sociologia moderna. Verona: Mondadori.

Norton, Bernard J. (1978). Karl Pearson and statistics: The social origins of scientific innovation. Social Studies of Science, 1978, 8/1, p. 3-34.

Pearson, Egon S. (1948) [1938]. Pearson, creador de la estadística aplicada. Buenos Aires: Espasa-Calpe.

Pearson, Karl. (1914-1930). The life, letters and labours of Francis Galton. Londres: Cambridge University Press (4 vols.) (vol. 1: 1914; vol. 2: 1924; vol. 3a: 1930; vol. 3b: 1930). Petty, William. (1691). The political anatomy of Ireland. Londres: Brown and Rogers.

Pitrone, Maria Concetta. (1996). Il sondaggio. Milão: Franco Angeli.

Porter, Theodore. (1986). The rise of statistical thinking, 18201900. Princeton: Princeton University Press. 
Quetelet, Adolphe. (1844). Recherches statistiques. Bruxelas: Hayez.

Richards, Joan. (1997). The probable and the possible in Early Victorian England. In: Lightman, Bernard (org.). Victorian science in context. Chicago: University of Chicago Press, p. 51-71.

Sinclair, John. (1791). The statistical account of Scotland. Edinburgh: William Creech.

Stigler, Stephen M. (1981). Gauss and the invention of Least Squares. The Annals of Statistics, 9/3, p. 465-474.

Stigler, Stephen M. (1999). Statistics on the table: The history of statistical concepts and methods. Cambridge, MA/Londres: Harvard University Press.

Toulmin, Stephen E. (1972). Human understanding. Princeton: Princeton University Press.

Von Bielfeld, Jakob F. (1770). Elements of universal erudition, containing an analytical abridgement of the sciences, polite arts, and belles lettres. Londres: G. Scott, for J. Robson and B. Law.

Von Zimmermann, Eberhard A. (1787). A political survey of the present state of Europe, in sixteen tables. Illustrated with observations on the Wealth and Commerce, the Government, Finances, Military State, and Religion of the several countries. Londres: C. Dilly.

Westergaard, Harald. (1932). Contributions to the history of statistics. Londres: P. S. King.

Young, Robert M. (1985). Darwin's metaphor: nature's place in Victorian culture. Cambridge: Cambridge University Press.

Yule, George U. (1938). Notes of Karl Pearson's lectures on the theory of statistics 1894-96. Biometrika, 30, p. 198-203. 


\section{DE OBJETO A MÉTODO: NOTAS HISTÓRICAS SOBRE ESTATÍSTICA E PESOUISA SOCIAL}

Resumo

Este artigo analisa o complexo processo histórico, social e cultural que acompanhou as mudanças de sentido do termo "estatística" (de objeto a método): desde o estudo comparativo dos Estados, no século XVIII, à descrição quantitativa da sociedade, no século XIX, até sua concepção como conjunto de instrumentos conceituais e operacionais para a análise quantitativa de dados a partir do século XX. Neste marco se reconstroem três tradições intelectuais cujas origens remontam a meados do século XVII - a aritmética política inglesa, a estatística univer sitária alemã e a teoria matemática das probabilidades francesa - com a finalidade de esclarecer as raízes profundas da teoria estatística moderna no pensamento científico europeu e pôr em evidência como o entrelaçamento dessas tradições, ao longo do tempo, foi redefinindo o sentido da estatística e sua relação com a pesquisa social empírica.

\section{FROM OBJECT TO METHOD: HISTORICAL NOTES ABOUT STATISTICS AND SOCIAL RESEARCH} thod): from the comparative study of States, in the eighteenth century, to the quantitative description of society in the nineteenth century, to a set of conceptual and operational instruments for the quantitative analysis of data in the twentieth century. In this framework, three intellectual traditions whose origins date back to mid-seventeenth century - British political arithmetic, German university Statistics and French probability theory - are reconstructed in order to illustrate the deep roots of modern statistical theory in the European scientific thought, and to highlight how the intertwining of such traditions, over time, redefined the meaning of Statistics and its relation to empirical social research.

\section{Palavras-chave}

Estatística;

Desenvolvimento histórico;

Pensamento científico;

Pesquisa social; Método.
Keywords

Statistics; Historical development; Scientific thought; Social research; Method. 